\title{
La arqueología subacuática en Gipuzkoa: panorama actual
}

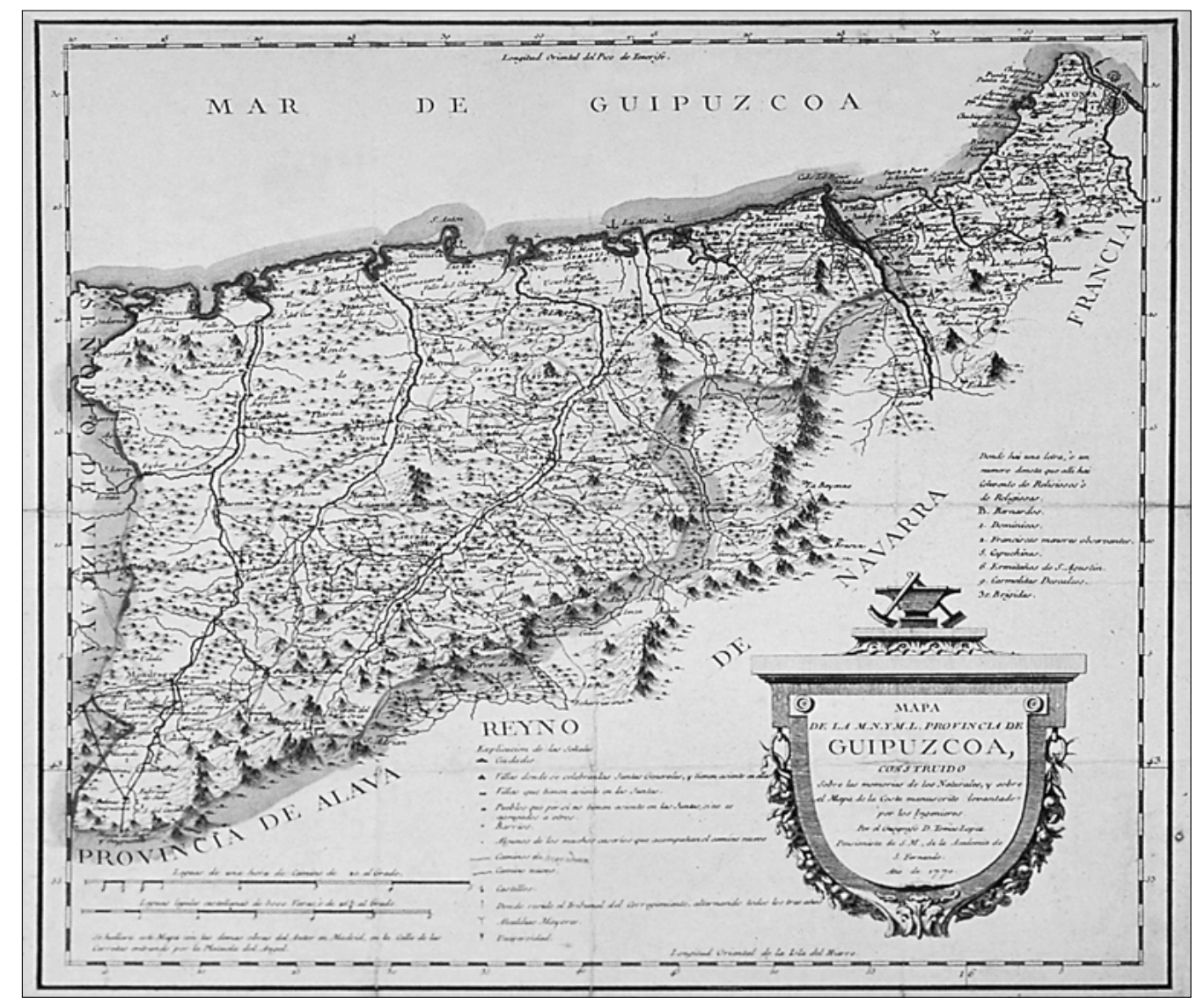

Mapa de Gipuzkoa del s. XVIII donde se aprecia su amplia fachada marítima

Ana Ma Benito Domínguez

Departamento de Arqueología Histórica

Sociedad de Ciencias Aranzadi

\section{Introducción}

A diferencia de la gran tradición de la arqueología subacuática en las costas del Mediterráneo, en el norte peninsular y concretamente en Gipuzkoa esta disciplina no está sino asentando sus primeras bases'. Precisamente las características del medio físico, es decir la costa y mar Cantábrico, van a condicionar el desarrollo de la navegación a lo largo de la Historia, aspectos que unidos a factores humanos, justificarán en parte la menor intensidad del tráfico marítimo, principalmente en época antigua, y por tanto como consecuencia la corta vida de la arqueología subacuática en estas latitudes.

\section{Condicionantes geográficos y medioambientales}

I. La plataforma continental vasca es muy reducida, alcanzándose a escasas millas de la costa los $200 \mathrm{~m}$. de profundidad, desde los que se forma un talud que llega a los $3000 \mathrm{~m}$. en la fosa de Cap Breton. Esta característica geográfica incide negativamente en la localización de pecios que puedan hallarse alejados de la costa y por tanto a grandes profundidades fuera del alcance de los medios técnicos habitualmente empleados en la actividad subacuática.

2. La fuerza e intensidad de las mareas así como las corrientes costeras superficiales, los fuertes vientos del NO que con frecuencia azotan esta costa y la acción de las galernas que caracterizan al Cantábrico, hacen que tanto los restos de naufragios, como las viejas estructuras portuarias se erosionen rápidamente, alterándose y fragmentándose, pudiendo en ocasiones, ser desplazados y depositados a varias millas de su lugar de origen. 
0
0
$+\pi$
2
0
0
0
2
0
0
0
0
0
0
0
2
2
0
1
$<$

Anclas líticas y potalas localizadas en diversos puntos de la costa gipuzkoana expuestos en

el Museo Naval de Donostia.
3. Los fondos costeros no son estables estando sometidos a grandes movimientos de arena, que cubren y descubren extensas zonas, formando dunas submarinas, que dificultan la situación de los hallazgos. Aunque se tomen las oportunas referencias en los restos localizados, al cabo de un tiempo, pueden hallarse bajo una gruesa capa de arena que obstaculiza su investigación, haciendo más costoso y largo el trabajo arqueológico.

4. La turbulencia y escasa visibilidad de las aguas, principalmente en las proximidades de la costa, debida a partículas de origen terrestre arrastradas por los ríos o desprendidas de los acantilados así como a los microorganismos que viven en estas aguas dificultan las labores de limpieza de los materiales excavados, el registro de datos así como la toma de fotografías.

Las frecuentes mares de fondo y la variabilidad de las condiciones marinas incide negativamente a la hora de la planificación de las labores arqueológicas así como de la realización de largas campañas.

5. La existencia de la cadena costera gipuzkoana, que se presenta como una barrera continua que impide la comunicación con el interior, salvo por las brechas practicadas por las rías que la perforan transversalmente. En éstas se van a instalar los enclaves portuarios, muy localizados y concretos a diferencia de las múltiples calas, bahías, fondeaderos y puertos que se suceden continuamente en la Costa Brava catalana o de las grandes playas abiertas en el litoral levantino.

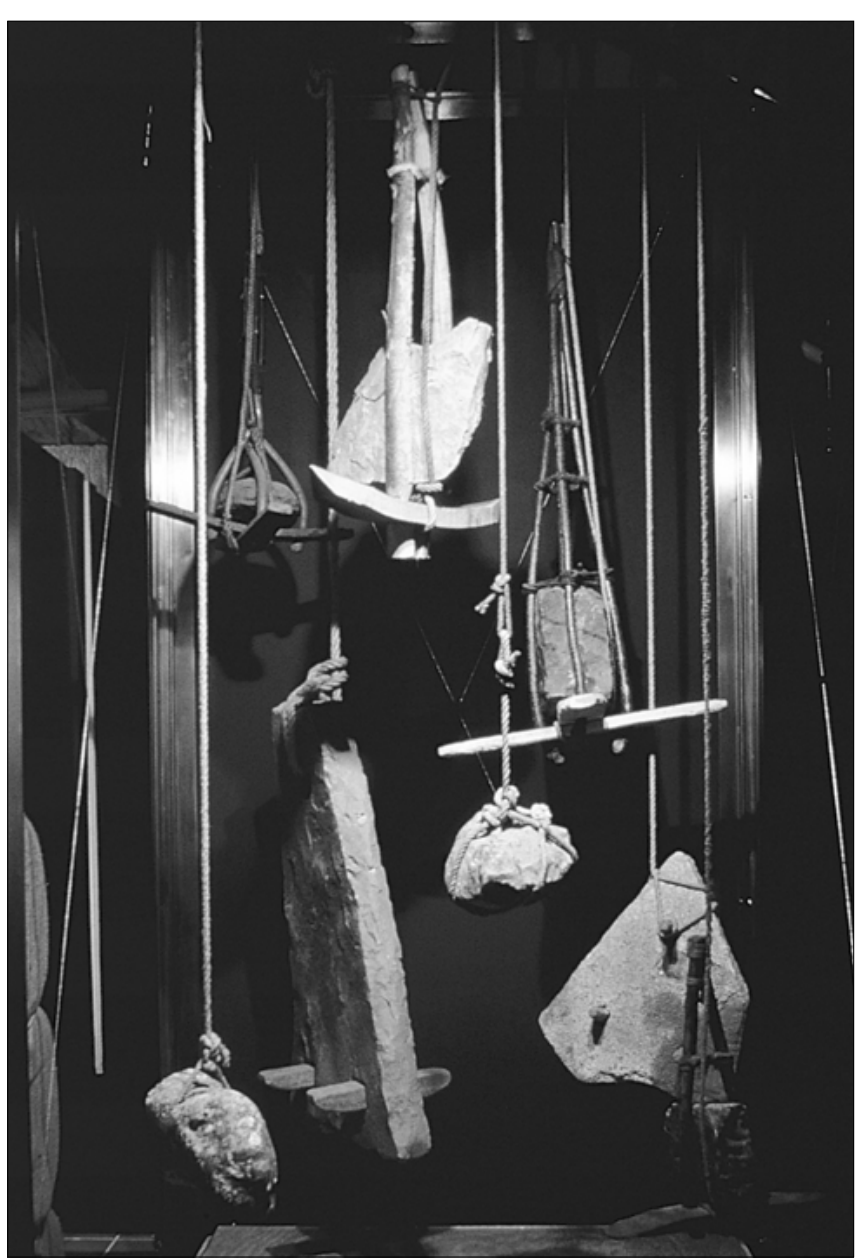

\section{Factores humanos}

Hay que mencionar la corta historia del buceo, tanto profesional como deportivo, en esta costa si se compara con la del litoral mediterráneo, si bien es verdad que en la última década esta situación ha cambiado substancialmente, proliferando los clubes y centros de buceo, así como aumentando la infraestructura para la actividad subacuática, añadiéndose nuevos establecimientos comerciales equipados con compresores y material de buceo que van jalonando la geografía gipuzkoana, aunque todavía no cubran todos los puertos.

Por otra parte resultaban insuficientes los estudios históricos elaborados sobre múltiples aspectos relacionados con la actividad marítima, que hubieran podido facilitar la labor de contextualización de los hallazgos aislados así como la programación de campañas arqueológicas. Este inconveniente se va subsanando en la medida en que se elaboran tesis doctorales y trabajos de investigación sobre comercio marítimo, construcción naval, pesca, infraestructura portuaria ${ }^{2}$, etc.

\section{La conservación y restauración de los materiales}

En los aspectos de conservación y restauración de los materiales arqueológicos subacuáticos, todavía Gipuzkoa no cuenta con una infraestructura que se dedique exclusivamente a estos aspectos debiendo recurrir a laboratorios extranjeros o de otras zonas del estado con el consiguiente inconveniente del desplazamiento de los materiales a centros tan alejados de la zona de actuación, siendo casi imposible realizar el traslado en el caso de grandes materiales y desaconsejable para su protección en otras ocasiones ${ }^{3}$.

Respecto a los análisis químicos y metalográficos si bien se pueden realizar en INASMET (Donostia), es frecuente el recurso a instituciones públicas como el ICRBC o en el CENIM de Madrid.

\section{Aspectos legales y organizativos}

A partir de la aprobación del Estatuto de Autonomía de la Comunidad Autónoma del País Vasco se transfieren las competencias en materia de Patrimonio histórico artístico, monumental y arqueológico. Desde ese momento es el Departamento de Cultura del Gobierno Vasco el responsable de los permisos de intervención arqueológica correspondiendo a las diputaciones forales la financiación económica.

Con la Ley de Patrimonio Cultural Vasco de 1990 se transfiere a las Diputaciones la facultad de regular los permisos de intervención sobre el patrimonio arqueológico así como mantienen la financiación económica de estas actuaciones ${ }^{4}$.

Debido a lo ajustado de los presupuestos oficiales, en determinadas intervenciones se hace preciso requerir 
la ayuda económica de otros departamentos, instituciones, e incluso financiación privada o personal.

Los materiales arqueológicos procedentes del medio subacuático se hallan actualmente en los fondos de la Sociedad de Ciencias Aranzadi, en INSUB, en la Sociedad Oceanográfica (Aquarium) o expuestos tanto en el Museo Naval de Donostia como en el de Santa Elena de Irún.

La actividad arqueológica desarrollada en el País Vasco se da a conocer anualmente, mediante los resúmenes que publica el Departamento de Cultura del Gobierno Vasco, en la revista Arkeoikuska, así como en las diversas publicaciones que editan las sociedades y museos anteriormente citados 5 .

\section{Historia de las recuperaciones}

Se pueden diferenciar dos etapas en la corta vida de la recuperación de materiales arqueológicos de procedencia subacuática así como de su sistemática y estudio en Gipúzkoa:

\section{Los hallazgos realizados hasta I96I}

La primera etapa llega hasta la década de los 60, siendo un periodo de hallazgos casuales que se producen sin tener conciencia de una labor arqueológica y en ocasiones desconociendo la importancia histórica de los restos, tratados simplemente como meros objetos con valor monetario o curiosidades.

- La mayoría de las veces estos hallazgos eran debidos al azar como el que se produjo en septiembre de 1945, cuando el vapor "Marichu" encalló en la bahía de Donostia propiciando el descubrimiento de los restos de dos embarcaciones con su artillería: cañones ingleses fechados en 1806, 1810 y 1813.

- En otras ocasiones fueron los buceadores pioneros de ambos lados de la frontera, que frecuentaban estas costas, principalmente las de Hondarribia y Donostia, quienes extraían anclas de piedra, de hierro, cerámica y cañones que pasaban a decorar sus viviendas.

En el mejor de los casos, pasando el tiempo estos materiales se recuperan y se estudian como el conjunto de monedas romanas que un coleccionista conservaba procedentes del cabo de Higer (Hondarribia).

Merced a recuperaciones esporádicas se ha formado un conjunto de huesos de ballena procedentes de diferentes puntos costeros que se hallan depositados en el Aquarium de Donostia.

- Otros hallazgos se han producido a través de las periódicas y continuas labores de dragado que se han realizado en los puertos, principalmente en el de Pasaia, propiciando la localización de diversos

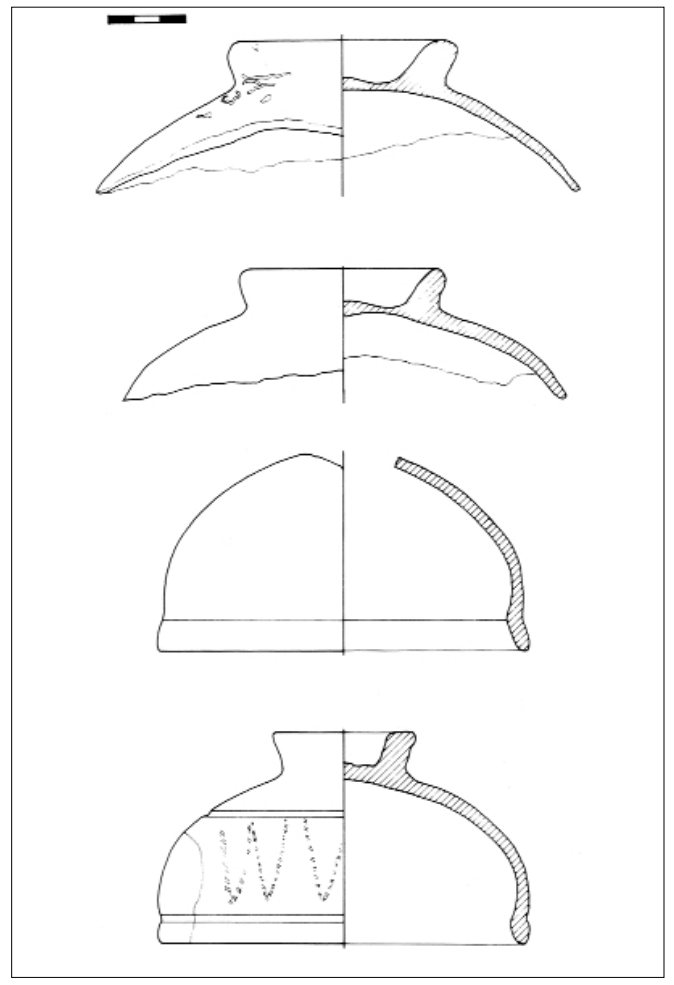

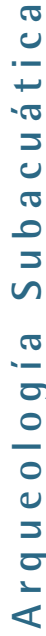

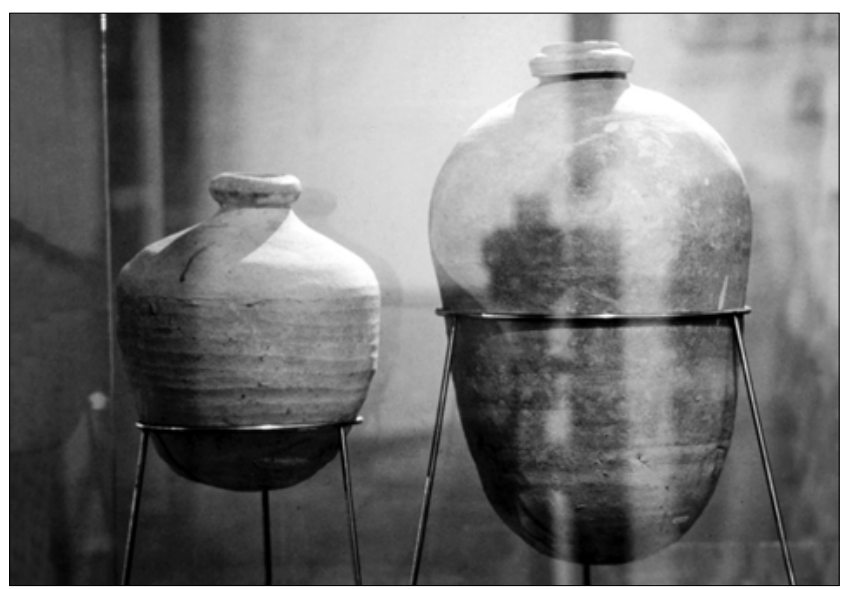

Vitrina del Museo Naval de Donostia donde se exponen una botijuela y una anforeta de materiales como monedas, cerámicas y en ocasiones piezas de artillería sobre las que se tienen escaprocedencia subacuática
Dibujo de varios fragmentos de cerámica, terra sigillata gris tardía, recuperados en el Cabo de Higer (Hondarribia) sas referencias.

\section{Actuaciones arqueológicas desde |96|}

Es a partir de 1961, fecha en la que se recuperan los primeros materiales submarinos junto al cabo de Higer, cuando se puede hablar del inicio de la arqueología subacuática en Gipuzkoa, aunque como se verá, en un primer momento todavía de una manera ocasional sin responder a un plan organizado.

A partir de la década de los 80 se inicia el inventario y catalogación de materiales arqueológicos subacuáticos así como se amplia el panorama de los estudios históricos sobre temas marítimos y se constituyen dos equipos arqueológicos que van a trabajar sistemáticamente hasta el presente, el de INSUB, dirigido por 
0
0
$+\pi$
2
0
0
0
2
0
0
0
0
0
0
0
2
2
0
1
$<$

Manu Izagirre y de la Sociedad de Ciencias Aranzadi, bajo mi dirección.

\section{Principales yacimientos submarinos}

Aunque toda la costa gipuzkoana presenta un gran interés en cuanto a la actividad arqueológica subacuática, se va a hacer un rápido periplo por los enclaves más productivos arqueológicamente, siguiendo la costa de oriente a occidente, desde Hondarribia hasta Getaria.

\section{El fondeadero del cabo de Higer y la desembocadu- ra del Bidasoa (Hondarribia)}

Junto a la desembocadura del fronterizo río Bidasoa y resguardada por el monte Jaizkibel se constituye la bahía de Hondarribia. En ella y junto al cabo de Higer se pone en evidencia en 196I lo que va a ser el primer yacimiento submarino de Gipuzkoa con el hallazgo de varios fragmentos cerámicos de época romana por parte del buceador profesional Tomás Hernandorena 6.

Desde la Sociedad de Ciencias Aranzadi y dirigidas por Jaime Rodríguez Salís, se efectúan diversas inmersiones en el fondeadero de Asturiaga entre 1969 y 1972. Entre 1973 y 1974, Rodríguez Salís continua en esta actividad acompañado por Manuel Martín-Bueno de la Universidad de Zaragoza, llevándose a cabo las primeras campañas de prospección sistemática de la zona, permitiendo localizar un túmulo de piedras que presenta restos de quilla y de mineral de hierro ${ }^{7}$, que según estos autores se correspondería con un pecio de época romana 8 .

Se reanuda la actividad arqueológica en este fondeadero en 1984, bajo la dirección de Mertxe Urteaga de la Sociedad de Ciencias Aranzadi en colaboración con Manu Izaguirre de INSUB. Estos trabajos permiten localizar un conjunto de piezas de bronce compuesto por unos apliques figurados representando a deidades clásicas, asas de jarras y otras piezas que debieron formar un único depósito de cronología romana 9 .

En 1985 se realiza la recopilación y catalogación del material cerámico procedente del Cabo de Higer, tanto del que se halla depositado en la Sociedad de Ciencias Aranzadi, como el que se encuentra expuesto en la Ermita Museo de Santa Elena así como algunas piezas de la colección de Tomás Hernandorena. A partir de esa fecha se abre una línea de trabajo en la Sociedad de Ciencias Aranzadi basada principalmente en la búsqueda, inventario y catalogación del material arqueológico de procedencia subacuática que se halla formando parte de colecciones particulares 10 .

Entre 1985 y 1992 se desarrollan continuas campañas de prospección en las aguas hondarribitarras, dirigidas por Izaguirre, con el objetivo de realizar una Carta Arqueológica Submarina de la bahía de Txingudi. En la campaña de 1990 se prospecta la desembocadura del Bidasoa entre el puerto Refugio y el puerto interior de la Marina sin resultados positivos. En 1991 se estudia morfológicamente la cala Asturiaga y se reconoce la cala Zarpia que aporta nuevos restos cerámicos y huesos de ballena. En 1992 continúan las labores de prospección en el espacio comprendido entre la playa y el puerto refugio así como la revisión de la zona situada aguas arriba en el Puntal, no hallándose material arqueológico significativo. Con motivo de la construcción del puerto deportivo de Hendaia se localizan diversos fragmentos de cerámica romana, común y terra sigillata, así como huesos de ballena "'.

A través de la labor realizada en estos años se ha puesto de manifiesto la importancia de la bahía de Hondarribia a lo largo de la Historia, debido a la abundancia y amplitud cronológica del material, que se sucede desde el inicio del Imperio romano con restos principalmente cerámicos como terra sigillata, paredes finas y ánforas, pasando por el Bajo Imperio representado a través del hallazgo de terra sigillata gris y ánforas tardías, continuando con los siglos oscuros del Medievo, hallándose anclas de hierro, hasta la Edad Moderna, de esta época se han recuperado cerámica esmaltada, anforetas y botijuelas y Época Contemporánea, con restos militares como balas de cañón, cuchillos, sables, etc. Por todo lo anterior no cabe duda de la utilización prácticamente ininterrumpida del Cabo de Higer como fondeadero natural y puerto refugio en la navegación de cabotaje a través del golfo de Bizkaia.

\section{La bahía de Donostia}

En la famosa bahía de la Concha a partir de los años 80 la sociedad INSUB realiza inmersiones sistemáticas que propician el hallazgo de un fragmento de ánfora romana.

En 1990, Izaguirre, inicia una serie de campañas de prospección con el objetivo de realizar la Carta Arqueológica subacuática de esa bahía siguiendo una metodología similar a la planteada para la de Txingudi. En la prospección de 1991 se localizan tres pecios, así como los restos de un buque carguero "Mamelena". En la III campaña desarrollada al año siguiente, se recuperan cerca de la bocana del puerto: botellas, pipas de caolín, fragmentos de cerámicas, balas de cañón, etc.; junto al paseo Nuevo se hallan tejas y ladrillos así como dos anclas líticas, una más se extrae en los alrededores de la isla de Santa Clara. En la campaña de 1996 en torno a esta isla se localiza una embarcación de madera con carenado de cobre así como se recuperan varias anclas líticas. En la de 1997 se constatan los restos de un posible cargamento de flejes a la altura de las instalaciones de la Cruz Roja del puerto. En la campaña de 1998 se reconoce el denominado "pecio de los relojes", un barco de madera de gran porte cuyo lastre ha quedado al descubierto, en la barra del paseo Nuevo se señalizan dos cañones de hierro, en otras zonas varias anclas de hierro y otras líticas. 


\section{Los barcos de la desembocadura del Oria}

Después de Donostia, tras el monte lgueldo se abre paso el río Oria, que forma una difícil barra a la entrada del puerto de Orio. En ella con motivo de las obras de dragado que la Dirección de Puertos y Asuntos Marítimos del Gobierno Vasco efectúa en 1992 se ponen en evidencia los restos de una embarcación con su cargamento. Según Izagirre ${ }^{12}$, quien va a dirigir la subsiguiente excavación de urgencia, se trata probablemente de un patache, de aproximadamente $10 \mathrm{~m}$ de eslora, de los siglos XVII o XVIII, que procedente de las minas de Somorrostro se dirigía a las ferrerías del río Oria pero no pudiendo superar la barra naufraga en la desembocadura del Oria. Se ha extraído toda la carga, entre 35 y 40 toneladas de mineral de hierro, así como gran parte de la estructura del barco, principalmente de roble.

Durante esa excavación se detectó la presencia de otra embarcación que hubo de ser excavada al año siguiente coincidiendo con nuevos dragados. Esta nave era menor que la anterior, extrayéndose su estructura lígnea. Cerca de ésta se halló la carga de una tercera embarcación, que no ha sido levantada. Con ocasión de estos trabajos se encontraron los restos de una cuarta embarcación que al estar protegida por la arena no se ha considerado necesario excavar.

La importancia de esta excavación estriba en la posibilidad de conocer por un lado el proceso de construcción naval de un periodo determinado y de un tipo específico de nave, como son estas pequeñas embarcaciones de carga así como añadir nuevos elementos al estudio de la navegación de cabotaje y el transporte de mineral a través del golfo de Bizkaia en Época Moderna.

\section{La bahía de Getaria y la nave de Iturritxiki}

El puerto de Getaria a diferencia de los demás gipuzkoanos no se enclava junto a un río sino al abrigo del monte San Antón, constituyendo un puerto refugio por excelencia y una segura bahía. En ésta en 1987. Ignacio Etcheverry e Iñaki Gutiérrez localizan cinco lingotes de cobre ${ }^{13}$.

A partir de 1988 se inician desde el Departamento de Arqueología Histórica de la Sociedad de Ciencias Aranzadi y bajo mi dirección diversas campañas de prospección y excavación en lo que se va a denominar yacimiento de Iturritxiki. En 1990 se efectúa la I campaña de excavación con la localización de nuevos sectores, el B, de donde se extraen nuevos lingotes y el $C$, en el que tras la excavación de una capa discontinua de concreciones se hallan, asociados a un lingote, múltiples alfileres, unas piezas en forma de asa y un magnífico ejemplar decorado de compás de embarcación ${ }^{14}$. En esta campaña se recuperan además, entre otros materiales, cuatro recámaras de bombarda muy concrecionadas, balas de cañón de metal, bolaños de diversos calibres, un rezón y un ancla. En las labores de revisión que desarrollamos habitualmente a lo largo del año con el objetivo de controlar el yacimiento así como con el fin de localizar nuevos materiales, se recupera una sección de asa de cañón de bronce del tipo de delfín, en superficie y sin otro material asociado, fuera de los límites conocidos hasta la fecha del yacimiento. En la campaña de 1992 se obtienen abundantes alfileres, asas, bolaños, varios fragmentos de anclas y otras concreciones metálicas, entre las que destacan dos conjuntos de calderos de cobre. Las siguientes campañas de excavación se centran en el sector $C$, que ha sido el más prolífero hasta la fecha. Se descubren además nuevos sectores que aportan otras concreciones, la estructura de una embarcación de madera así como diverso material disperso en labores de prospección.

Paralelamente a la realización de las últimas campañas de excavación se ha iniciado la limpieza y restauración de las múltiples concreciones pertenecientes a las

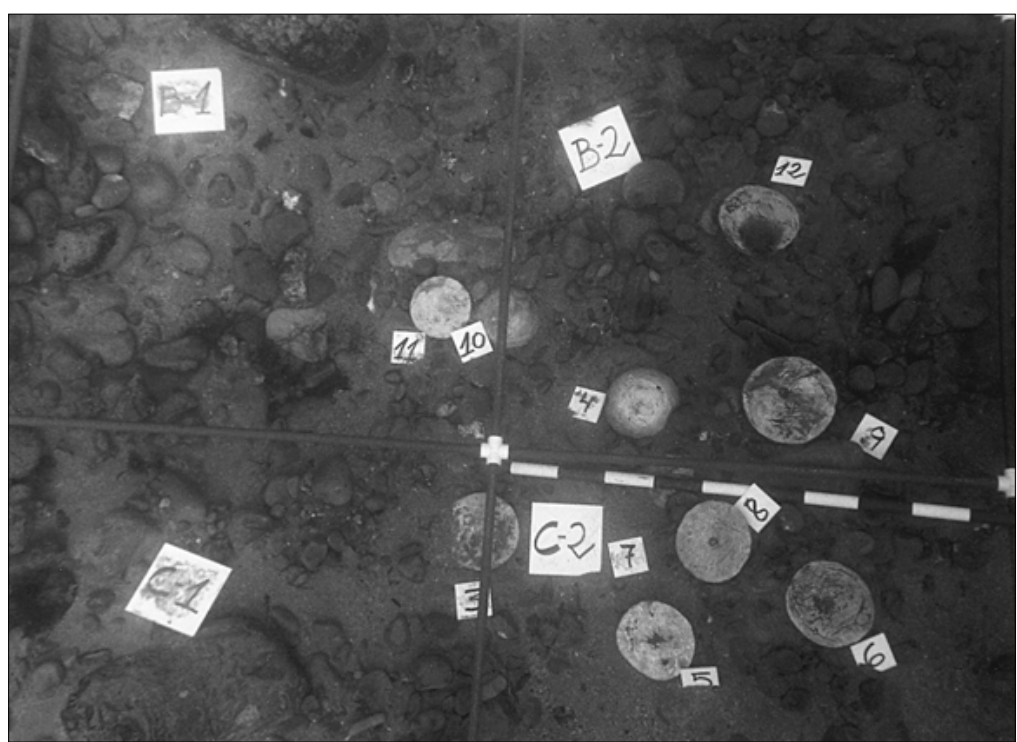

Excavación de Iturritxiki

campañas anteriores obteniéndose nuevos materiales, como una espada con su funda, una moneda portuguesa del reinado de Manuel I, piezas de una armadu(Getaria): se aprecian los lingotes de cobre procedentes de la carga de la urca flamenca

ra, etc.

Tras el análisis de la labor de estos años se puede concluir que existen tres contextos principales y diferenciados en la zona que se ha prospectado:

\section{Nave de Iturritxiki: la urca flamenca}

El primero y más interesante, del que forman parte la mayoría de los materiales rescatados, es el cargamento de una nave, que según la documentación hallada se trata de una urca flamenca, que se hunde en Getaria entre los últimos años del siglo $\mathrm{XV}$ y los primeros del $X V \mid{ }^{15}$. Hay que reseñar que la información recogida no es contemporánea al momento del hundimiento sino de años posteriores, refiriéndose al hecho de la recuperación casual de parte de la carga. Esta se define de manera bastante precisa ya que se recupe- 
0
0
$+\pi$
2
0
0
0
2
0
0
0
0
0
0
0
2
2
0
1
$<$

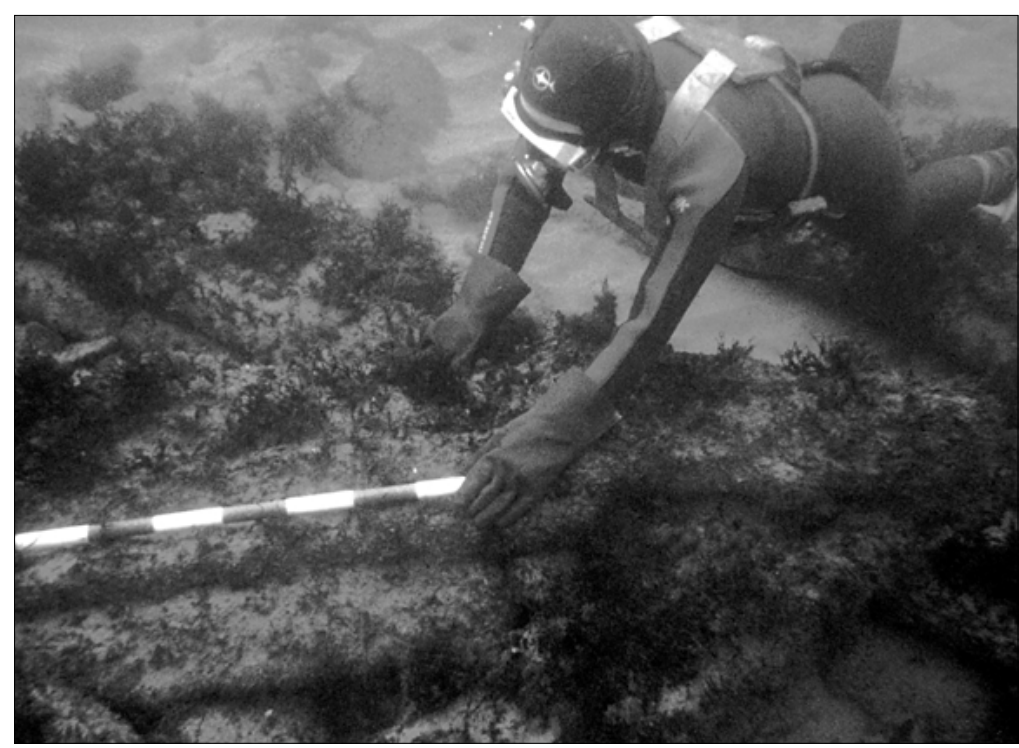

Visión de parte del cargamento de la embarcación que transporta barras de ferrería hundida en la bahía de Getaria ran panes de buen cobre, argollas de azófar, es decir latón, calderos de cobre y objetos de mercería.

El cargamento de esta nave que naufraga en Getaria consiste básicamente en una materia prima, el cobre en forma de lingote, de los que se han podido constatar tres tipos: dos de forma semiesférica y el tercero de sección de cono, estando en la mayoría de los casos sellados. Teniendo en cuenta los tipos y sellos reconocidos, se puede pensar que se trata de tres o cuatro fundidores que trabajan probablemente en una misma zona minera y considerando los grandes focos mineros del Cu del momento en Europa podrían proceder o bien de Gran Bretaña o más probablemente de Centro Europa, de Alemania.

Además de la materia prima, la urca llevaba en sus bodegas productos manufacturados derivados de ella

(de cobre, bronce y latón) como las asas, argollas o "manillas", los calderos y los alfileres. Probablemente todo este cargamento procedía de una nave afletada por portugueses que desde un puerto flamenco se dirigía a las costas africanas para proceder al intercambio con los nativos de estas mercaderías por marfil, oro y esclavos y que desgraciadamente naufraga en Getaria por causas naturales ${ }^{16}$.
Como era frecuente en la época dados los peligros de la piratería, esta nave debió de ir armada como lo indican las recámaras de bombarda y la abundante munición de piedra, bolaños, hallada junto a ellas.

\section{Segundo contexto: batalla de 1638 y restos militares diversos}

Getaria, debido a su situación estratégica fue plaza fuerte y cumplió un importante papel en la defensa de la costa vasca, de este pasado militar también queda constancia en las aguas de la bahía, a través de hallazgos aislados a nivel superficial como el fragmento de asa de cañón de bronce, munición de hierro, anclotes y varios rezones; piezas estas últimas, que además de acompañar a las embarcaciones fueron utilizadas para el rescate del material existente en las naves naufragadas durante las campañas de salvamento que seguían al hundimiento.

Estos restos pudieran pertenecer a alguno de los galeones de la flota de Lope de Hoces, que refugiada en la concha de Getaria, es hundida por la armada francesa en $1638{ }^{17}$ en plena Guerra de los Treinta Años ${ }^{18}$ así como a las labores que inmediatamente después se efectuaron para la recuperación del material, especialmente cañones y anclas.

\section{Carga de una pequeña nave con hierro}

En la campaña de 1989 se localiza en un lugar definido de la bahía de Getaria, un conjunto de piezas de hierro forjado de sección cuadrada de aproximadamente I,50 $\mathrm{m}$. de largo, que han resultado ser barras de ferrería. Se hallan completamente concrecionadas presentando una apariencia de tipo cilíndrico y en ocasiones formando amasijos entre ellas. Constituyen posiblemente parte de la carga de una nave, de pequeño tamaño, tipo zabra, pinaza o patache, que procedía de una de las múltiples ferrerías de este territorio, probablemente de las del Oria. A esta embarcación de Getaria, le pudo suceder lo mismo que a las cuatro embarcaciones descubiertas en la desembocadura del Oria, ya que intentando refugiarse en el puerto naufragó siendo golpeada contra las rocas. 
I. Este artículo está basado, resumido y actualizado, en BENITO, Ana Ma: "La arqueología subacuática en el País Vasco: una disciplina emergente", Itsas Memoria, I, 1996, pp. 277-310, Donostia-San Sebastián.

2. El Gobierno Vasco ha iniciado la publicación de una colección sobre la historia de los puertos vascos, habiéndose editado los volúmenes correspondientes a los puertos de Bermeo, Armintza, Getaria y Ondárroa.

3. Actualmente hay que reseñar que la Diputación Foral de Gipuzkoa destina un ajustado presupuesto anual para la restauración de materiales arqueológicos, entre los que se incluyen los de procedencia subacuática en Arteleku, bajo la dirección del restaurador Georgio Studer.

4. IZAGUIRRE LACOSTE, M.: "Política de financiación de las actividades arqueológicas en Gipuzkoa", Jornadas Internacionales de Arqueología de Intervención, Donostia, Diciembre 1991, pp. 461465.

\section{Aranzadiana, Munibe y Itsas Memoria.}

6. Que fueron entregados a la Sección de Arqueología de la Sociedad de Ciencias Aranzadi y publicados por MEZQUÍRIZ DE CATALÁN, M.A.: "Notas sobre arqueología submarina en el cantábrico". Munibe, 16, pp. 24-41. San Sebastián.

7. Los resultados de los análisis de las muestras recogidas son publicados por MARTíN-BUENO, M.: "Análisis de mineral en cargamento de pecio romano", Bajo Aragón Prehistoria, 3. Zaragoza, 1981.

8. MARTÍN-BUENO, M., RODRÍGUEZ SALIS, J.: "The anchorage of El Cabo de Higuer (Fuenterrabía, Guipúzcoa)", The International Journal of Nautical Archaelogy and Undenwater Exploration, 1975, 4,2, pp. 331-333 y MARTíN-BUENO, M.: "Hallazgos cerámicos submarinos en Fuenterrabía (Guipúzcoa)". Sautuola II, 1976-1977, pp. 375-382. MARTíN-BUENO, M., IZAGUIRRE, M., CASADO, J.L., MEJUTO, R., SENEN, F.: "La arqueología subacuática en las costas del norte y noroeste peninsular: estado de la cuestión". VI Congreso Internacional de Arqueología Submarina. Cartagena, 1982. pp. 33-58.

9. Siglos II o III d. C. según URTEGA, M.M.: "Los bronces romanos de Higer. Hondarribia. Guipuzcoa". Munibe, 1988, p. 120. San Sebastián.

10. Veáse al respecto entre otros, BENITO DOMÍNGUEZ, A.M. : "Cerámicas del yacimiento submarino del Cabo de Higuer (Hondarribia)". Munibe, 40, 1988, pp. 123-163. San Sebastián y "Sigillata gris tardía del fondeadero del Cabo de Higuer (Fuenterrabía)". 8è Col.loqui Internacional d'Arqueologia de Puigcerdà, La romanizació del Pirineu, Puigcerdà 1988, pp. |19-130.
1 I. Los materiales de las primeras campañas de prospección efectuadas por INSUB se hallan depositados en la Sociedad de Ciencias Aranzadi y han sido catalogados por A.M. Benito Domínguez (Arkeoikuska, 1989, pp. 193-194), quien destaca entre ellos la existencia de un fragmento de terra sigillata Ritterling 8 así como una forma Rigoir 6 con decoración estampada de terra sigillata gris tardia.

12. Arkeoikuska, 1992, pp. 322-329.

13. Se trata en realidad de tochos de fundición cuyo peso oscila entre los 3 y $12 \mathrm{Kg}$. Los análisis químicos efectuados han dado valores de Cu del 94,75 a 99,38 \% con impurezas despreciables, así mismo los análisis metalográficos nos aportan datos referidos a una fundición de cobre de alta calidad, aunque se utilicen moldes coyunturales (arena, piedra, etc.).

14. Se halla en perfecto estado de conservación, llevando decoración excisa. Los análisis químicos realizados indican que está constituido por latón, material muy frecuente en los instrumentos científicos desde la Edad Media.

15. Esta procede del Archivo General de Simancas, pero desgraciadamente es muy breve y parcial dificultándose la continuación de la búsqueda documental por la ausencia de las fuentes municipales, dado que el Archivo Municipal de Getaria se quema en 1836, durante la Primera Guerra Carlista.

16. Teniendo en cuenta que las "manillas" eran utilizadas como primitivas monedas por los índigenas africanos y que comienzan a fabricarse en serie en Europa al constatar la importancia que tenían en el intercambio comercial, así como que el comercio del momento con las costas africanas era monopolio de la corona portuguesa.

17. En el verano de ese año, las tropas francesas bajo el mando del principe de Condé ponen sitio a Hondarribia. Ante esta situación Felipe IV envía a Lope de Hoces al frente de la escuadra de La Coruña con el objetivo de levantar el sitio de la plaza fuerte. Sin embargo a la altura de Getaria esta escuadra es atacada por la armada francesa del Atlántico. Tras intensos combates se produce la derrota de la flota española, hundiéndose 12 galeones y provocando 3.000 muertos (estas cifras varian sensiblemente según las fuentes bibliográficas que se consulten).

18. Sobre este hecho histórico no hay bibliografía específica aunque si abundante información sobre el contexto en que se produce, el sitio de Hondarribia de 1638, pudiéndose consultar entre otros MORET, J.: Empeños del valor y bizarros desempeños o sitio de Fuenterrabia, 1638. Anales del Reyno de Navarra, T. VIII. Biblioteca de la Gran enciclopedia Vasca, 1969 y FERNÁNDEZ DURO, C.: Armada española desde la unión de los reinos de Castilla y Aragón. T. IV. Madrid, Museo Naval, 1972, pp. 169-188. 